\title{
Die Godsbegrip in die filosofie van Spinoza
}

\author{
J D GERICKE
}

\section{Ter Inleiding}

Verlede jaar en wel op 21 Februarie 1977 het wysgere dwarsoor die wêreld die sterfdag van Benedictus de Spinoza 300 jaar gelede herdenk. Die departement Wysbegeerte van die Universiteit van Pretoria het by wyse van 'n uitstalling in die Merensky Biblioteek hierdie filosoof vereer. Vanjaar herdenk ons die vyf en twintigste jaar wat professor PS Dreyer aan die departement Wysbegeerte verbonde is. Aangesien daar verlede jaar nie 'n artikel oor Spinoza in hierdie tydskrif verskyn het nie, het die skrywer dit goedgedink om die twee gebeurtenisse by wyse van hierdie stuk werk aan mekaar te koppel. Daar sal veral gelet word op die belangrike plek wat Spinoza in die moderne wysbegeerte ingeneem het, maar vanweë die aard van hierdie tydskrif sal die klem hoofsaaklik val op hierdie denker se metafisiese beskouing waarin die Godsbegrip 'n uitstaande plek inneem.

\section{Die plek van Spinoza in die geskiedenis van die Moderne Wysbegeerte}

Spinoza was 'n kind van die sewentiende eeu - 'n tydperk wat gekenmerk was deur baie omwentelinge op natuurwetenskaplike gebied. Ongelukkig kan dieselfde nie van die wysbegeerte gesê word nie. Ses jaar na die geboorte van Spinoza het die beroemde werk van Galilei, Dialoghi della nuove scienze verskyn. Hiermee gepaardgaande moes die reeds gevestigde Aristoteliese wêreldbeeld plek maak vir'n meganistiese opvatting wat dan ook die fondament van die rasionalistiese wysbegeerte gevorm het. So byvoorbeeld word gevind dat René Descartes wat as die vader van die moderne wysbegeerte bekend staan en ook die "leermeester" van Spinoza was, 'n nuwe wysgerige stelsel ontwerp het aan die hand van die wiskundige metode terwyl Leibniz die fisika as grondslag van die metafisika beskou het. Op ' $n$ dag het Spinoza bemerk dat hy ook deel van hierdie nuwe lewens- en wêreldbeskouing was en wel in so 'n mate dat hy besluit het om sy teologiese studies prys te gee ten gunste van die natuurwetenskappe en veral die fisika. Die nuwe wêreld wat vir hom oopgegaan het, moes noodwendig aanleiding gee tot nuwe opvattings ten opsigte van die geestes- en natuurgebeure wat in stryd was met die godsdienstige opvattings van die tyd. Nieteenstaande sy verbanning uit die Joodse Kerk, het Spinoza volgehou met 'n meganistiese verklaring van die syn. Alles fungeer en word in stand gehou deur ma- 
tematiese prinsipes waaraan selfs die siel van die mens ondergeskik is.

Onderliggend aan hierdie soms oordrewe beheptheid met die kousaalwetmatige verklaring van die heelal word gevind dat die sewentiende eeu ook gekenmerk word deur 'n kalmte en rus waarna gesoek was ná die vloedgolf nuwe idees en ontdekkings van die Renaissance. Die taak wat die rasionaliste dus aan hulleself opgedra het, was om die bestaande denke te orden en te sistematiseer deur middel van 'n redelike deurgronding van die werklikheid. "Analysis was replaced by construction. The great importance of this for thought was that it now became possible to see clearly what exactly was involved in the point of view to which the Renaissance and the new science had led. These positions were established with a dogmatic certainty unknown to the intellects of a former age, who had never taken exact account of individual principles and their bearings. That which previously had only floated, more or less vaguely, before men's minds was now formulated with express consciousness. The new structures were to reach as high as those which had been pulled down. The natural impulse, always more or less active to the human spirit, to synthesise all ideas established as valid, expressed itself here with a vigour and energy, coupled with an originality, to be found in no other period in the history of modern philosophy. Problems were stated, moreover, with a freshness and distinctness unparalled either before or since." 1

Hierdie nuwe gesindheid teenoor die wetenskap wat eintlik neerkom op 'n nugtere en verantwoordelike houding teenoor die mens en wat hy deur middel van die beoefening van die wetenskap tot stand wil bring, is veral in die wysbegeerte van Spinoza baie opmerklik. Op'n unieke wyse word daar agter die fenomenale werklikheid gekyk in 'n poging om die verborge strukture van die nomenon te verklaar. Dit moet egter genoem word dat elke rasionalis homself met 'n substansieleer besig gehou het, maar soos verwag kan word, het elkeen hierdie vraagstuk op 'n eiesoortige manier benader en sy eie vertolking daarvan gegee. Descartes het in 'n dualisme tussen gees en liggaam verval terwyl Leibniz as 'n uiterste dogmatiese denker beskou word. Alhoewel die metafisika van Spinoza ook sekere tekortkominge het, het hy die beste daarin geslaag om 'n harmonie tussen Natuur en Denke te bewerkstellig. Vandaar dan ook die opvatting dat hy as die sentrale figuur van die sewentiende eeu beskou word.

\section{Die taak van die wysgeer}

Spinoza was een van die weinige filosowe wat vanuit ' $n$ besondere lewens- en wêreldbeskouing 'n wysgerige denksisteem ontwerp het. 
Daarom is dit belangrik om eers vas te stel wat sy gesindheid teenoor die wysbegeerte was om sodoende 'n beter begrip te kry van die synsproblematiek waarmee hy homself besig gehou het. Die opmerking is reeds gemaak dat Spinoza ' $n$ heel besondere plek in die geskiedenis van die wysbegeerte ingeneem het en wel ten aansien van die wyse waarop hy die taak van die wysbegeerte geformuleer het en dan hieruit 'n heel besondere wysgerige denkrigting ontwerp het. Die wysgeer behoort nie iemand te wees wat 'n spul "ewige waarhede" kwytraak en dit dan aan die mensdom voorhou nie. Alhoewel Spinoza in baie opsigte nie daarin geslaag het nie, het hy altyd daarna gestreef om die wysbegeerte van sy formalisme vry te maak en dit met ' $n$ meer bruikbare stelsel te vervang. Geen wonder dat hy sy wysbegeerte as ' $n$ lewensleer beskou het waarin "leer en leven, idee en handelen" op mekaar ingryp. Dit moes as "een handleiding dient voor het ethisch volmaakte leven, waaruit de mens zou kunnen leren, hoe door inzicht in de eenheid en de noodzakelijkheid van het $\mathrm{Al}$, verbonden met de liefde tot het Oneindige, de behoefte aan geluk volkomen kan worden bevredigd". ${ }^{2}$ Waar dit vir Descartes gegaan het om antwoorde te vind op vrae soos: "Wat is waar?" Watter waarhede kan ons in die werklikheid ontdek en is hierdie waarhede vir die mens toeganklik?, gaan dit eerder vir Spinoza om die beantwoording van die vraag hoe en op welke wyse die wysgeer insig kan verkry in die ware of synswerklikheid van God, wêreld en die mens. Vandaar dan ook sy monisme met 'n eties - praktiese en misties-religieuse strekking - 'n metafisika waardeur gepoog word om 'n etiek te ontwerp waarby die ontologie en kennisleer betrek word. Teen hierdie agtergrond moet die Spinozisme gesien word waardeur "een oorspronkelijke visie van de eenheid van het Oneindige en het eindige, van God en wêreld, word omgezet in redelijke begrippe, die op hun beurt weer tot die eenheidsvisie terugvoeren"

\section{Die Metafisika}

\section{God en Natuur}

Op die vraag: "Wie is God? het Spinoza geantwoord:

"My God, my God, daar is geen God - daar is geen God van die Jode nie, daar is geen God van die Christendom nie, daar is geen Thomistiese of Cartisiaanse God nie - daar is geen God nie. Alles is God. Daar is geen ander God behalwe die kosmiese Syn self nie. Daar is geen God buite die wêreld nie, dit wil sê, buite die Universum of die Natuur nie. Die Natuur is God, God is natuur'3

Hiermee gepaardgaande word God in definisie 6 as volstrekte oneindigheid gedefinieer ${ }^{4}$ : 
“Onder God verstaan ek die volstrekte oneindige wese; dit wil sê, 'n substansie wat uit ' $n$ oneindige aantal attribute bestaan wat elkeen op sigself 'n ewige en oneindige wese uitdruk."'s

Met hierdie definisie van God het Spinoza sy metafisika aangekondig wat tesame met dié van Descartes en Leibniz as die "filosofie van die essensie" getipeer kan word omdat elkeen op sy eie manier 'n antwoord gesoek het op die vraag: "Wat is Substansie (essensie)?" Nou kan geargumenteer word dat hierdie beskrywing van God as die Absolute Substansie nie veel van dié van Descartes verskil nie. Hier word onmiddellik gedink aan laasgenoemde se opvatting dat God die Ewige Substansie is waaruit die "res cogitans" en die "res extensa" as substansiële verskyningsvorms emineer. Dit bring meteens ' $n$ verdere ooreenkoms tussen hierdie twee denkers aan die lig naamlik dat die laaste strofe van Spinoza se definisie:: "Natuur is God, God is natuur" (Substansie = God en Natuur) eintlik 'n weerspieëling is van die Cartisiaanse naturalisme. In die sesde bepeinsing sê Descartes, "Onder die begrip Natuur in die algemeen (natura generaliter spectata) verstaan ek niks anders as God self of die samehang van alle geskape dinge (co-ordinatio) uit en deur God"'. Wat die leer aangaande die attribute betref, kom 'n verdere "ooreenkoms" tussen Spinoza en Descartes aan die lig en wel dat beide denkers dit eens was dat die Substansie (wat dit ookal mag wees) uit 'n aantal attribute bestaan. Volgens Descartes was dit die voorwaarde om te sê dat die syndes van die Syn substansies is.

Hoe dit ookal sy, kon Descartes nie daarin slaag om die dualisme tussen God en Natuur (denke en uitgebreidheid) uit die weg te ruim nie. Die oënskylike rede hiervoor is dat hy God (die Absolute Substansie), as 'n buite-die-wêreld-bestaande Substansie beskou het. God is dus 'n ongeskape Substansie wat bo en teenoor die geskape substansie bestaan - dus 'n Substansie wat buite die "natuurlike lig van die ratio" bestaan. Spinoza daarenteen kon nie anders as om in te sien dat dit slegs die Natuur is wat bestaan en dat God dus die $\mathrm{Na}$ tuur is omdat daar buite die Natuur niks bestaan nie aangesien dit nie gedink kan word nie. Daarom is die Natuur naturend - dit bring sigself voort - dit is 'n ewige en tydlose ontvouing van die Substansie.

Die eerste gedagte wat nou by 'n mens opkom, is dat Spinoza daarin geslaag het om die hele synsorde (die goddelike sowel as die natuurlike, die geestelike sowel as die stoflike) deel van die ratio te maak. Niks ontglip of val buite die bestek van die rede van die mens nie. Uit die aard van die saak sal so ' $n$ beskouing meer aanvaarbaar wees as dié van Descartes. Die probleem is egter dat Spinoza die metafisiese beskouings van Descartes geheel en al omvergewerp het. Vir laasgenoemde bestaan daar 'n onaantasbare en onkenbare AlEne-Substansie naamlik God, terwyl Spinoza die God van Descartes 
"lewendig" wou maak. Hy lewe uit die Natuur - Hy is aktief in die Natuur werksaam - Hy is dus die Natuur.

Die alternatief wat Spinoza hier stel, maar veral die wyse waarop hy die begrippe "God" en "Natuur" hanteer het, laat die vraag ontstaan of ons nie hier te doen het met 'n polarisasie van substansies nie. Spruit die tese nie uit die anti-tese voort nie? Aangesien ons hiervan mag aflei dat Idees uit ' $n$ vreemde of andersoortige synsbron afkomstig is, kan dit neerkom op'n ontkenning van die suiwere Idee van die Syn. Ons mag verder argumenteer - al sê ons van die Natuur dat dit ' $n$ ewige uit sigself ontvouende substansie is, bly dit Natuurlike Syn teenoor ' $n$ "Geestelike" of Ewige Syn. Die gevolg hiervan sal noodwendig wees dat ons tot die besef sal kom dat die betekenisvolle funksies wat die Godsbegrip behoort te hê, nou skielik in die niet verdwyn het. Die uiters radikale denker sal selfs sê dat al die positiewe aspekte van die substansieleer in 'n panteïstiese sysverklaring verlore geraak het.

Spinoza sal natuurlik so ' $n$ bewering ten sterkste ontken deur te wys op die funksie en betekenis van twee verdere begrippe wat hy implementeer ten einde die blywende eenheid tussen nomenon en fenomenon te verseker. Met verwysing na die wêreldwording uit God, sê Spinoza, "In God bestaat noodwendig een idee van alles wat uit zijn wezen met noodwendigheid voortvloei." "Het begrip van Gods wezenskenmerken heeft niet die wezenskenmerken op zichself tot grond, maar God zelf, voorzoover het Bewustzijn is."

"Hetgeen door zichself bestaat en als grond van zichzelf begrepen word, namelijk de wezenskenmerken (attributen) van God, maakt de 'Scheppende Natuur' (Natura naturans) uit." "Tot de "Geschapen Natuur' (Natura naturata) behoort evenwel hetgeen uit de noodwendigheid van een wezenskenmerk Gods voortvloeit."

"Hetgeen noodwendig uit de volstrekte onbepaaldheid van Gods wezen voortvloeit, zijn de onmiddellijke openbaring van God, krachtens welke alle andere openbaringen volgen die evenmin zonder God kunnen bestaan óf begrepen worden."7

In hierdie gedeelte lê Spinoza twee aspekte van die kosmiese Syn aan die leser voor, naamlik die essentia (Natura naturans) en die existentia (Natura naturata) waardeur hy wil bewys dat daar slegs een Substansie is. Eersgenoemde is die verborge wese van die Syn (die Skeppende Natuur) terwyl die existentia die verskyningsvorm (die Geskape Natuur) daarvan is. Uit God se skeppende werksaamheid maak Hy Homself aan die mens bekend. God is sy werke en sy werke is in Hom. Hieruit is dit duidelik dat ons hier te doen het met ' $n$ volledige parallellisme tussen die liggaamlike en geestelike asook tussen die uitgebreide wêreld (extentio) en die denke (cogitatio). Dan is dit ook duidelik dat Spinoza die paradoksale oorsaaklikheidsleer van Descartes in gedagte gehad het. Daarom word gevind dat hy telkens 
die woorde "skeppende" en geskape" kwalifiseer. Antoine Arnauld het reeds daarop gewys dat Descartes se analise van die begrip "selfveroorsakende" nie bevredigend toegeskryf word nie. Indien God (of die Natuur in die geval van Spinoza) die oorsaak van alles is, moet $\mathrm{Hy}$ ook die gevolg daarvan wees omdat die oorsaak die gevolg in tyd voorafgaan. In God is daar egter geen onderskeid tussen die hede, verlede en toekoms nie, nog minder tussen moontlikheid en werklikheid.

Spinoza was natuurlik bewus van die probleme wat die begrippe "naturans" en "naturata" kan veroorsaak. Daarom verkies hy nie om die bekende woord creatio (ex nihilo) te gebruik nie, maar liewers'n generatio van die Natura naturata uit die Natura naturans. Die naturari kom uit die Natura voort terwyl die Natura naturans en Natura naturata'n ewige kontinuum bly handhaaf ('n kontinuum tussen Skepper en Skepping).

Wanneer Spinoza God as die skeppende beginsel (Natura naturans) agter alle syndes noem, bedoel hy hiermee dat God die oorsaak van alles is. Nie 'n eensoortige oorsaak wat tot 'n andersoortige gevolg aanleiding gee en dus as twee geskeie substansies geïnterpreteer moet word nie. Die gevolg is eerder ' $n$ openbaring van die aard van die oorsaak. Moontlik sal dit beter wees om van ' $n$ logiese onderskeid te praat. Derhalwe is God causa emanativa en cause activa. Die Natura naturans bestaan nie buite die Natura naturata nie. God is dus eerder cause immanens as causa transiens.

Alhoewel Spinoza met hierdie kousaliteitsgedagte die dualisme van Descartes gedeeltelik opgehef het, bly sekere bepalings van die Transendente oorsaak sowel insigself paradoksaal te wees asook in stryd te wees met die Christelik-teologiese opvatting (soos deur hom ook erken word). Deur God causa immanens, causa per se te noem, wil dit nie sê dat Hy causa libera is, soos Spinoza wel voorgee nie. Die woord causa verbind as't ware die vryheid as oerfenomeen aan die wesentlike of substansie van God. Anders gestel, vryheid is 'n Synskomponent wat gans anders is as gewone of partikuliere wilsvryheid of keusevryheid. Die substansieleer van Spinoza laat met ander woorde nie toe dat vryheid aan God toegeskryf of toegesê word nie aangesien God nie gebonde is nie. Vryheid spruit eerder voort uit die Natuur en dus uit God self. Substansie is immers God en Natuur. Van ' $n$ goddelike wil is daar ook geen sprake nie (dus twee afsonderlike syndes nie) want in Hom vind daar slegs 'n selfontvorming plaas volgens kousale wette wat inherent deel van sy Wese is. Alle wording, aktiwiteit, ja selfs alle denke is van 'n kosmiese Syn (Natuur) afhanklik en dit is alles gepredestineer ingevolge kosmiese wette. Die vraag wat nou ontstaan, is of hierdie "praktikularisme" nie aanleiding gee tot 'n dualisme tussen God en Natuur (die veroorsakende Substansie) aan die een kant en die effektiewe synstrukture aan die ander kant nie. 


\section{Die Attribute}

Dit laat my onwillekeurig dink aan Spinoza se attributeleer wat enersyds ' $n$ uitbouing is van sy substansieleer, maar ook ' $n$ poging is om nader aan die denk- en leefwêreld van die mens te kom en andersyds wil hy die siel en liggaam dualisme in die filosofie van Descartes ophef. Spinoza definieer die attribuut soos volg: "Per atttributum intelligo id, quod intellectus de substantia percipit tanquam essentiam constituens" $^{\text {"8 }}$ en "per Dei attributa intelligendum est id quod durnae substantiae essentiam exprimit, hoc est id, quod ad substantiam pertinet". ${ }^{9}$ Die eens verborge (Cartesiaanse) Substansie (God) word deur die attribute of eienskappe Denke en Uitgebreidheid aan ons bekend gemaak. " $Z \mathrm{Zj}$ zijn de uitdrukkingswijzen, de openbaringswijzen van het eeuwige $Z_{i j n}$, en zijn dus in hun eigen aard, voorzover ze het $\mathrm{Zijn}$ op een bepaalde wijze uitdrukken, oneindig. $\mathrm{Zij}$ zijn in hun soort eeuwig en onveranderlijk". ${ }^{10}$ Terwyl Spinoza dus die Absoluutheid van God handhaaf, wil hy die wesensvorm daarvan skoubaar maak. Deelname of partisipasie in en met God is dus moontlik. Ons kan byvoorbeeld sy skepping waameem terwyl ons ook daaroor kan dink. Dit wil egter nie sê dat aangesien die denke en uitgebreidheid ' $n$ openbaring van God is (dus uit ' $n$ enkele substansie voortkom), ons nou die denkfenomeen van die materiële fenomeen kan deduseer nie. "Not only is it a matter of experience that we know only two attributes, but the definition of the concept of attribute also rests upon experience, namely on the fact... that the mental and the material are each to be understood according to their own laws.* The difference between these two worlds is thus irreducable; we cannot deduce the mental from the material, nor the material from the mental; but within the mental world for itself, and within the material world for itself, we can point to coherence and causality". ${ }^{11}$ Höffding haal Spinoza in hierdie verband soos volg aan: "So long as things are regarded as mental phenomena (modi cogitandi) we must (debemus) explain the order of Nature or the causal connection by the attribute of thought alone; and so long as we regard them as material phenomena (modi extensionis), we must (debet) explain the whole order of Nature by the attribute of extension alone". ${ }^{12}$ God maak Homself dus aan ons bekend deur middel van die twee attribute, naamlik denke (cogitatio) en uitgebreidheid (extensio). Daar is ook ander eienskappe van God wat aan ons bekend is, soos byvoorbeeld ewigheid, enigheid, onveranderlikheid, almagtigheid ensovoorts maar aangesien dit nie wesentlike eienskappe is nie, noem hy dit nie attribute nie, maar propria (dus eienskappe van 'n laer orde). Dit is egter ironies dat ten spyte van hierdie onderskeiding (wat aanleiding gee tot verdere paradokse), Spinoza nog volgehou het met die gedagte van die ewigdurende eenheid van Substansie en Modus. "eie beklemtoning 
Propria kan ook aan attribute toegeskryf word, aangesien eersgenoemde ook ewig, noodsaaklik, onveranderlik, ondeelbaar, ensovoorts is. Dit moet seker toegegee word dat aangesien die attribute die wesenskenmerke van God uitdruk, dit essensiële propria moet besit, maar waar eindig 'n mens met sodanige reductio ad absurdum (in hierdie geval eienskappe (attribute) van eienskappe (proprial)? Beslis nie by sy leerstellings ten opsigte van die modus (affectiones) en modi (verskyningsvorm van die Substansie) nie, aangesien dit'n ope vraag bly of Spinoza daarin geslaag het om 'n eenheid tussen die infinitus en die singularia te bewerkstellig. Wat sy beskrywing van die fenonemenale wêreld betref (die singularia), merk ons verder op dat hy die mens met sy liggaam en siel ook by die attribute insluit, maar as gevolg van die afwesigheid van 'n "medium" (idee - wat baie vaag beskryf word) kan die twee mekaar nie regstreeks beïnvloed nie. Hierteenoor word verklaar dat "van de menselijke geest bestaat een voorstelling in God, voorzover hij de oorzaak is van de voorstellingen die samen de geest ${ }^{*}$ vormen. ${ }^{13}$ Tevens bestaat er in God een voorstelling van het lichaam voorzover hij de oorzaak is van het lichaam. ${ }^{14}$ God is de causa efficiens van het wezen en van het bestaan van die mens. $\mathrm{Hij}$ is eveneens de oorsaak van de idea, die hy heeft van die mens". 15

Ten spyte van hierdie onderliggende dualisme in sy substansieleer, moet erken word dat Spinoza altyd gepoog het om 'n suiwere Godsbegrip aan die leser voor te hou. Die taak wat hy in die inleidende paragrawe van die Ethica aan homself opgedra het, het hy met sukses uitgevoer. Dit is naamlik dat hy die wese van God en sy eienskappe wil verklaar, en verder "dat $Z$ ijn bestaan noodwendig is; dat $\mathrm{Hij}$ eenig is; dat Hij alleen krachtens de noodzakelijkheid van $\mathrm{Zijn}$ wezen bestaat en werkt; dat $\mathrm{Hij}$ is de vrije oorsaak van alle dingen, en op welke wijse Hij dat is; dat alle dingen in God zijn en dermate van Hem afhanklijk, dat zij zonder Hem niet kunnen bestaan, noch begrepen word - en; eindelijk, dat alles door God is voorbeschikt, en zulks niet uit vrijen wil of onbeperkte willekeur, maar krachtens Gods volmaakte natuur of Zijn oneindige mogendheid". ${ }^{16} \mathrm{Dit}$ is egter net jammer dat Spinoza nie bevredigende antwoorde kon verstrek op kennislerige problematiek van sy tyd nie.

\section{Slotgedagte}

Wanneer beweer word dat Spinoza een van die uitstaande sisteemdenkers van die sewentiende en agtiende eeue was, kan so ' $n$ stelling tot baie wanindrukke en misverstande aanleiding gee. Die rede hiervoor is dat ons hiervan kan aflei dat hy daarin geslaag het om deur middel van een of ander unieke wysgerige stelsel die problematiek rondom die synsvraag op ' $n$ bevredigende en geldige wyse die hoof *eie beklemtoning 
gebied het. Nou moet onmiddellik bygevoeg word dat Spinoza 'n nugtere denker was, en daarom het hy gesorg vir 'n nuwe benadering en gesindheid ten opsigte van die "filosofie van die substansie". Nogtans het daar baie probleme onopgeklaard agterweë gebly. Daarom is die skrywer van mening dat die grootheid van Spinoza nie soseer in sy wysbegeerte gesoek moet word nie, maar in die filosoof agter sy filosofie.

Word daar byvoorbeeld gekyk na sy Godsleer, dan word dit algaande duidelik dat Spinoza dit nie soseer as 'n substansieleer aangebied het nie, maar eerder as 'n lewensleer. Professor S Rappaport som dit raak op wanneer hy sê:

"For Spinoza philosophy is not only an intellectual pursuit, but a way of life. He was a sage as well as a thinker and practiced the doctrine in which he deduced from his teaching. Rarely does one find such perfect harmony between a philosopher's teaching and his actual life as in the case of Spinoza. He lived for the truth he preached". ${ }^{17}$

Daar is niks in die materiële werklikheid wat ons tot 'n gelukkige lewe kan lei nie. Al wat daar vir die mens dus oorbly, is om volkome kennis van God en sy skepping (Natuur) te bekom. Die hoogste deug is die liefde vir God, want hierdeur leer ons onsself met al ons gebreke en tekortkominge ken.

Die hele doel van die "Ethica" is om die mens na die waarheid en na God te lei. Dit geskied deur die redelike weg te volg. Die grondliggende gedagte hieragter is dat die verborge strukture van die Syn nie deur middel van misties-intuïtiewe denke aan ons kenbaar gemaak sal word nie, maar deur nugtere rasionele denke. Niks wat ons om ons waarneem, is bloot toevallig nie, maar dit is daar met ' $n$ bepaalde doel wat sy oorsprong in 'n eerste oorsaak het - Goddelike oorsaak.

1. Höffding, H, A history of modern philosophy, New York: Dover Publications, 1955 p 209.

2. Sassen, F, De betekenis van Spinoza, Artikel gepubliseerd in "Wijsgerig perspectief op maatschappij en wetenschap, $\mathbf{p} 74$.

3. Vertaalde aanhaling uit 'n artikel deur JG van der Bend, "Het probleem subjectobject in de wijsbegeerte van Spinoza", in die "Tijdschrift voor Filosofie. Nr 1 Maart 1969.

4. Spinoza se hoofwerk "Ethica" bestaan uit 'n aantal aksiomas, definisies, stellings en bewyse.

5. Vertaling van definisie 6.

6. Vertaling van 'n gedeelte van die sesde bepeinsing.

7. Societas Spinozana: God - Wereld - Leven, Gedachten van B de Spinoza, Gravenhage NV Drukkery, 1935 p 32.

8. Ethica I: Def IV

9. Ethica I: prop XIX

10. Het probleem Subject-Object in de wysbegeerte van Spinoza bl 350. 
11. Höffding bl $\mathbf{3 1 0}$

12. Hōffding bl 310

13. Ethica II: Def I

14. Ethica II: Prop XX

15. Ethica I: Prop XXV

16. W G van der Tak, Spinoza bl 93.

17. Rappaport S, "Spinoza's Spiritual worth", Uit die tydskrif Jewish Affairs, Vol 37 Nr 2, Februarie 1977: p 11. 